\title{
Time-dependent mechanical behavior of lime-mortar masonry
}

\author{
Els Verstrynge • Luc Schueremans • Dionys Van Gemert
}

Original article DOI: 10.1617/s11527-010-9606-8

\begin{abstract}
An extensive experimental program has been set up to characterize the time-dependent deformation behavior of masonry, subjected to the creep failure mode. Different types of short-term creep tests were performed on small masonry specimens, which were constructed with air-hardening lime mortar. To assess the influence of the carbonation process on creep behavior, several specimens were subjected to accelerated carbonation. The time-dependent deformations are modeled using a viscoelastic, rheological model which includes damage effects. The applicability of the model is validated by comparing theoretical and experimental results and extending the time frame to long-term predictions. Good agreement was found between experimental and simulated time-dependent deformations. The accuracy of the proposed model is estimated by including the scatter on the most important material parameters in the analysis.
\end{abstract}

Keywords Masonry · Time-dependent behavior . Experimental testing · Creep modeling

\section{Introduction}

The time-dependent deformation of masonry constructions is an important aspect of the material behavior

\section{E. Verstrynge}

Department of Civil Engineering, Kasteelpark Arenberg 40, 3001 Heverlee, Belgium

Tel.: +32-16-321987

Fax: +32-16-321976

E-mail: els.verstrynge@bwk.kuleuven.be

L. Schueremans

E-mail: luc.schuremans@bwk.kuleuven.be

D. Van Gemert

E-mail: dionys.vangemert@bwk.kuleuven.be which has to be considered when assessing the safety of a historical masonry monument. Due to relatively low material strength and high dead weight, tall historical masonry constructions are often subjected to load levels which are rather high compared with the compressive strength of the materials involved. The long-term mechanical behavior of historical masonry has been subject of numerous studies. Stability of historical masonry under creep deformations has been assessed by Binda [1], Anzani [2] and Pina-Henriques [3]. Modeling the combined effects of creep deformation, humidity and age at loading using rheological models was addressed by Van Zijl [4] and Choi [5]. Ferretti [6] also included the influences of carbonation effects. As many of these studies indicate, the awareness on the importance of obtaining data regarding masonry's time-dependent behavior was increased by various collapses of historical masonry structures over the past decades $[1,7]$.

As the description of masonry's time-dependent behavior requires rather complicated and time-consuming tests, the amount of experimental data found in literature is limited $[8,9]$. Often, experimental data from creep tests on other brittle materials, such as concrete, are used to verify theoretical models $[4,10]$. Especially full data sets, involving information on the scatter of the obtained results, are lacking. This is in marked contrast with the characteristics of the material involved and the manner in which creep behavior is generally modeled. As the inhomogeneity, which is intrinsic to the lay-out of masonry, introduces a large spread on its material properties, the scatter on the experimental results should be included in any analysis or modeling process. Furthermore, the scatter on in-situ masonry characteristics will often be larger than on results from laboratory experiments, as defects such as weath- 
ering, voids and larger fluctuations in material strength of older masonry are not included in experimental data.

To integrate the deviation in material characteristics in the structural modeling and stability assessment, a probabilistic framework should be used. This was done by Garavaglia [11] by defining a limit state based on the allowable strain rate. In this paper, only the scatter on the most important material parameters will be included in the analysis. A future aim is to perform a probabilistic analysis, where the structural model defines the limit state. Some preliminary results on this issue were presented in [12].

The experimental test program, presented in this paper, involves compressive tests and different types of short-term creep tests on two series of test specimens. Both series were constructed with lime mortar and lowstrength clay bricks. To obtain an adequate data set, at least three test specimens were used for each type of test and each mortar type. The test specimens and experimental set-up are discussed in Section 2 and 3. The results of the test program are presented and analyzed in Section 4.

The structural modeling of masonry's time-dependent behavior with a viscoelastic model is discussed in Section 5. The model is based on the rheological Burgers model with damage, as proposed by Papa and Taliercio [10]. An adapted, even simplified definition is used to describe the evolution of damage in order to account for experimentally based parameter results. A set of model parameter values, calculated from the experimental results, is used as input for the simulations. The applicability of the proposed model for the prediction of the strain-time evolution is estimated by comparing theoretical and experimental results. Additionally, the time frame is extended to long-term predictions, see Section 6.

\section{Test program}

The test program involved a series of compressive tests and different types of accelerated creep tests on small masonry specimens. All tests were performed on a Dartec hydraulic press, with a maximum load of $5000 \mathrm{kN}$. To increase the accuracy, a subcell was used to limit the maximum load to $500 \mathrm{kN}$, which was sufficient for the masonry columns. The evolution of the imposed forces was programmed in a script which automatically controlled the pressure of the hydraulic system. This way, the creep tests, which each had a duration of more than 24 hours, should not be paused at night. Deformations were recorded with one horizontal and one vertical Linear Voltage Displacement Transducer (LVDT) on each side of the specimen, see Fig. 1. The strains indicated

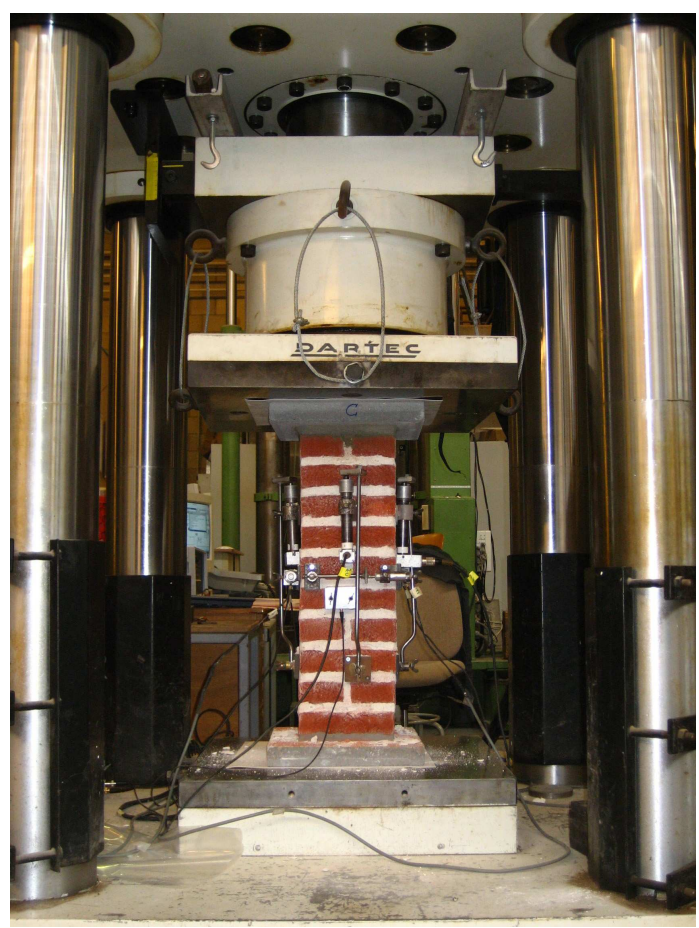

Fig. 1 Experimental setup for compressive tests and creep tests

in further analysis are calculated as the average value of the strains measured at the four monitored sides of each specimen.

\subsection{Compressive tests}

Compressive tests were carried out in a deformationcontrolled set-up with a deformation velocity of $10 \mu \mathrm{m} / \mathrm{s}$. The results of these compressive tests were used to characterize the material's mechanical behavior and to define a loading scheme for the creep tests.

\subsection{Creep tests}

Different types of short-term creep tests were performed to quantify the masonry's time-dependent behavior at different stress levels. In order to keep the stress level constant and immobilize the relaxation effect when deformations occurred, a load controlled set-up was used. Typical accelerated creep tests (ACT) were performed following the loading path indicated in Fig. 2(a). In a first step, the load was increased to a level lower than $50 \%$ of the average compressive strength, $f_{c}$, of the masonry. The load is then kept constant for a period of three hours and subsequently increased again. The size of the load increase steps is reduced as soon as a load level of $70 \%$ is reached. This loading scheme is repeated until failure of the specimen. 


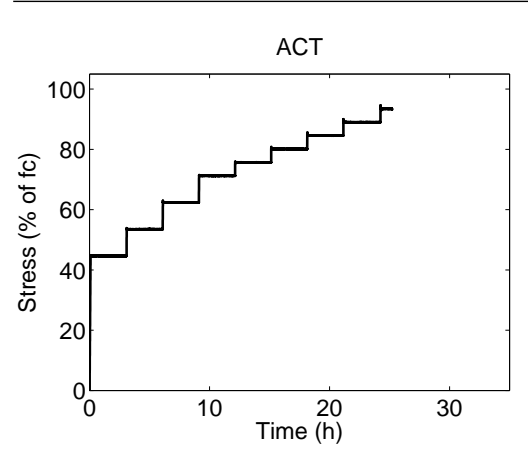

(a) Accelerated creep test



(b) Cyclic accelerated creep test

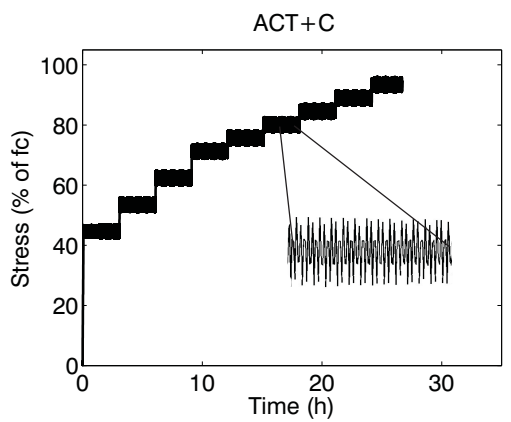

(c) Accelerated creep test with additional, small cyclic load

Fig. 2 Typical loading path for different types of short-term creep tests

The two other types of short-term creep tests are variations on this loading scheme:

- Cyclic accelerated creep tests (CACT): Before each stress increase, the specimen is unloaded in order to quantify the effect of the damage accumulation on the value of the Young's modulus. The loading path is indicated in Fig. 2(b).

- Accelerated creep tests with an additional cyclic loading $(\mathrm{ACT}+\mathrm{C})$ : An additional small cyclic loading with an amplitude of $5 \mathrm{kN}$ and a frequency of $0.125 \mathrm{~Hz}$ is imposed on top of the loading scheme of the ACT in order to simulate the effect of wind loading, see Fig. 2(c).

\section{Materials and test specimens}

For the experimental program, new masonry specimens were constructed. However, the materials were chosen to be representative for historical masonry. An air-hardening lime mortar was used, with a composition of 1 volume part lime on 2.5 volume parts sand in order to approximate the composition of a historical lime mortar. In practice, when the compounds of a historical lime mortar are investigated, compositions can be found ranging from 2 volume parts lime on 1 volume part sand to 1 volume part lime on 4 volume parts sand [13]. The sand chosen for the construction of the masonry columns was a fine grained river sand $0 / 2$. The mortar composition is indicated in Table 1. Different mortar mixtures were prepared and from each mixture, three masonry specimens were constructed. Small variations on the mortar composition are indicated through the standard deviation in Table 1.

Relatively low-strength bricks were chosen, type Spanish red, with dimensions $188 \times 88 \times 48 \mathrm{~mm}$ (length $\times$ width $\times$ height) and an average compressive strength of $8 \mathrm{MPa}$.
Table 1 Composition of the air-hardening lime mortar: average (standard deviation)

\begin{tabular}{llll}
\hline component & $\begin{array}{l}\text { river sand } \\
(\mathrm{kg})\end{array}$ & $\begin{array}{l}\text { lime } \\
(\mathrm{kg})\end{array}$ & $\begin{array}{l}\text { water } \\
(\mathrm{l})\end{array}$ \\
\hline average (st. dev.) & 1 & $0.168(0.001)$ & $0.230(0.003)$ \\
\hline
\end{tabular}

\subsection{Test specimens}

Masonry columns with dimensions $19 \times 19 \times 60 \mathrm{~cm}$ (length $\times$ width $\times$ height) were constructed, composed of 10 brick layers, with two bricks per layer and a mortar thickness of $1 \mathrm{~cm}$. The masonry was pointed just after construction with the same mortar mixture, used for the bricklaying. All masonry specimens were stored at a temperature of $20 \pm 1{ }^{\circ} \mathrm{C}$ and a relative humidity of $60 \pm 5 \%$ for three months before testing.

\subsection{Accelerated carbonation}

To investigate whether the time-dependent carbonation process has an influence on the creep behavior of the masonry, half of the total amount of specimens were subjected to accelerated carbonation (B-type masonry). The other half of the specimens were enabled to carbonate naturally and, consequently, were not fully carbonated at the time of testing (A-type masonry).

The accelerated carbonation process was performed by placing the specimens in an acclimatized box for a period of 4 weeks. The conditions in the box were kept constant at a temperature of $20 \pm 1^{\circ} \mathrm{C}$ and a relative humidity of $60 \pm 5 \%$. These conditions were chosen as they are most beneficial to the carbonation process [14] and they are similar tot the storing conditions of the uncarbonated specimens. The carbon dioxide level was increased by inserting $\mathrm{CO}_{2}$ directly into the box. The $\mathrm{CO}_{2}$ level was monitored by means of a gas analyzer and fluctuated around $6 \pm 3 \%$. The evolution of 


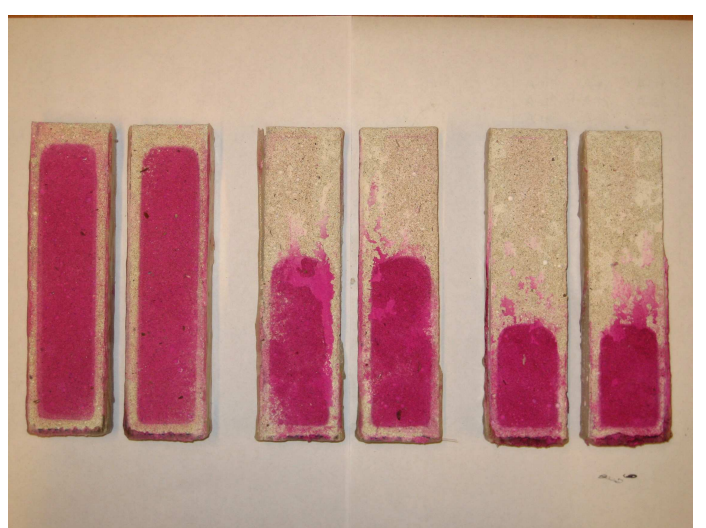

Fig. 3 Phenolphthalein test on mortar beams

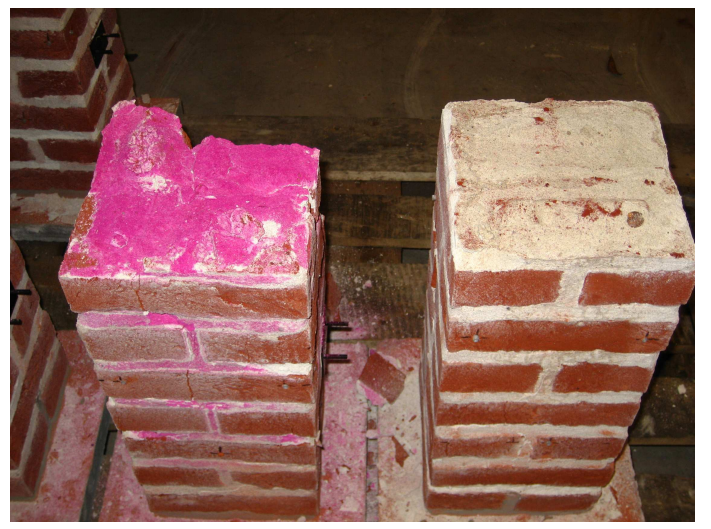

Fig. 4 Phenolphthalein test on masonry specimens. Uncarbonated A-type masonry (left) and fully carbonated B-type masonry (right)

the carbonation dept in time was observed by periodically splitting a mortar beam, which had been sealed with paraffin except for one end of the specimen, and spraying phenolphthalein to detect the progress of the carbonation depth. Fig. 3 presents three small mortar beams, which were tested after $1,2.5$ and 4 weeks of exposure to the atmosphere with increased $\mathrm{CO}_{2}$ concentration. The carbonation front progresses from the free end (top of the specimens) inwards and after 4 weeks, a dept of $10 \mathrm{~cm}$ is reached. A small carbonated zone can be observed at the sealed edges of the mortar beams, as they were only covered with paraffin at the age of one month.

After the execution of the creep tests, two checks were performed in order to confirm that the masonry specimens had been fully carbonated. Phenolphthalein was sprayed on all specimens and the difference can be observed very distinctly when a specimen subjected to accelerated carbonation (specimen type B) is compared to a naturally carbonated masonry specimen (specimen type A). For the former, the phenolphthalein does not change color, indicating that all Calcium Hydroxide $\left(\mathrm{Ca}(\mathrm{OH})_{2}\right)$ has reacted with Carbon Dioxide $\left(\mathrm{CO}_{2}\right)$ to

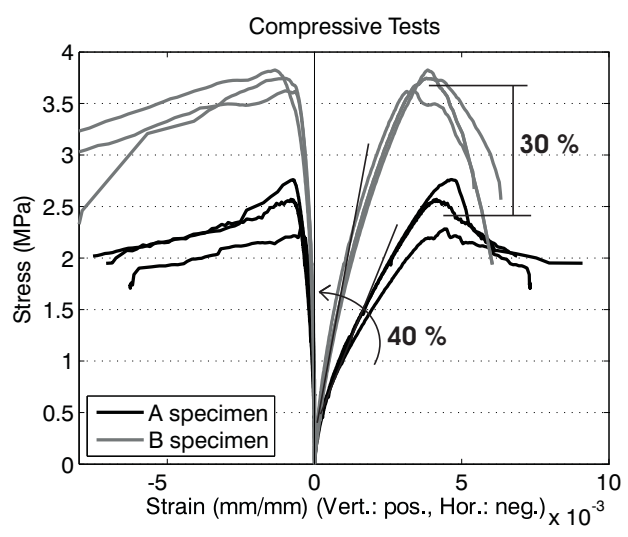

Fig. 5 Resulting stress-strain behavior from compressive tests

form Calcium Carbonate $\left(\mathrm{CaCO}_{3}\right)$. Considering the latter, only a small zone of $0.5-1.5 \mathrm{~cm}$ remains white and has thus carbonated, Fig. 4. Secondly, a thermogravimetric analysis (TGA) has been performed to investigate the composition of the mortars. From this analysis, the same conclusion could be drawn as from the phenolphthalein test.

All specimens, carbonated as well as uncarbonated have been loaded at the age of three months. It can be assumed that no hygral equilibrium is reached in the specimens at this stage, so an interaction between the mechanisms of shrinkage and creep could occur to result in an additional drying creep. The individual mechanisms could be studied by testing sealed specimens, as proposed by [4], but this can not be combined with the applied test set-up. However, since the influence of moisture is outside the scoop of the presented experimental program, all specimens were stored and tested in constant environmental conditions, so the influences will be small and the total deformations are assumed to represent basis creep. Thus, the experimental program focuses on the influence of the stress level on creep deformations, without considering temperature and moisture fluctuations. For information on the effect of moisture on creep deformations, the reader is referred to $[4$, $6,15]$.

\section{Results}

The data obtained during the compressive tests and short-term creep tests are presented below. The strains are calculated as the average of the values monitored by the LVDT's on the four sides of each specimen.

\subsection{Mechanical behavior under monotonic loading}

From Fig. 5, it can be observed that the test specimens which were fully carbonated (B-type) have a compres- 
Table 2 Results from compressive tests on A- and B-type specimens: average (standard deviation)

\begin{tabular}{lll}
\hline $\begin{array}{l}\text { specimen } \\
\text { type }\end{array}$ & $\begin{array}{l}\text { number of } \\
\text { specimens }\end{array}$ & $\begin{array}{l}\text { compressive strength } \\
(\mathrm{MPa})\end{array}$ \\
\hline A & 3 & $2.54(0.24)$ \\
$\mathrm{B}$ & 3 & $3.73(0.10)$ \\
\hline
\end{tabular}

Table 3 Overview of results of short-term creep tests: average (standard deviation). $f_{c}$ is the average compressive strength from the monotonic compressive tests

\begin{tabular}{llll}
\hline $\begin{array}{l}\text { specimen } \\
\text { type }\end{array}$ & $\begin{array}{l}\text { number of } \\
\text { specimens }\end{array}$ & $\begin{array}{l}\text { maximum load } \\
\text { at failure } \\
(\mathrm{MPa})\end{array}$ & $\begin{array}{l}\% \text { of } f_{c} \\
(\%)\end{array}$ \\
\hline A-type & & $2.22(0.10)$ & 88 \\
\hline ACT & 3 & $2.25(0.12)$ & 89 \\
CACT & 3 & $2.09(0.33)$ & 82 \\
ACT + C & 3 & & \\
\hline B-type & & $3.37(0.17)$ & 90 \\
\hline ACT & 3 & $3.36(0.30)$ & 90 \\
CACT & 3 & $3.69(0.09)$ & 99 \\
ACT + C & 3 &
\end{tabular}

sive strength which is approximately $30 \%$ higher than the strength of the A-type specimens. Also, a $40 \%$ increase in Young's modulus is observed and the B-type masonry responds in a slightly more brittle manner.

The results of the compressive tests are summarized in Table 2 and indicate a rather low scatter, which is a consequence of the very careful approach during the preparation of the mortars and construction of the specimens in laboratory conditions. The compressive strength of a specific mortar type, $f_{c}$, is calculated as the average result of the compressive tests for each mortar type respectively.

\subsection{Time-dependent deformation behavior}

The different types of short-term creep tests are performed as described in Section 2.2 and the resulting maximum stress levels obtained during the tests are presented in Table 3 . The maximum stress values, obtained during the accelerated creep tests (ACT) and cyclic accelerated creep tests (CACT) are around 90 $\%$ of the compressive strength values. If stresses are applied at lower loading rates, such as is done during a short-term creep test, lower maximum stresses and larger strain values are found at failure. The results indicate that a decrease of the loading rate, or, in other words, increase of the loading time from half an hour to 24 hours, decreases the compressive strength with 10 $\%$.
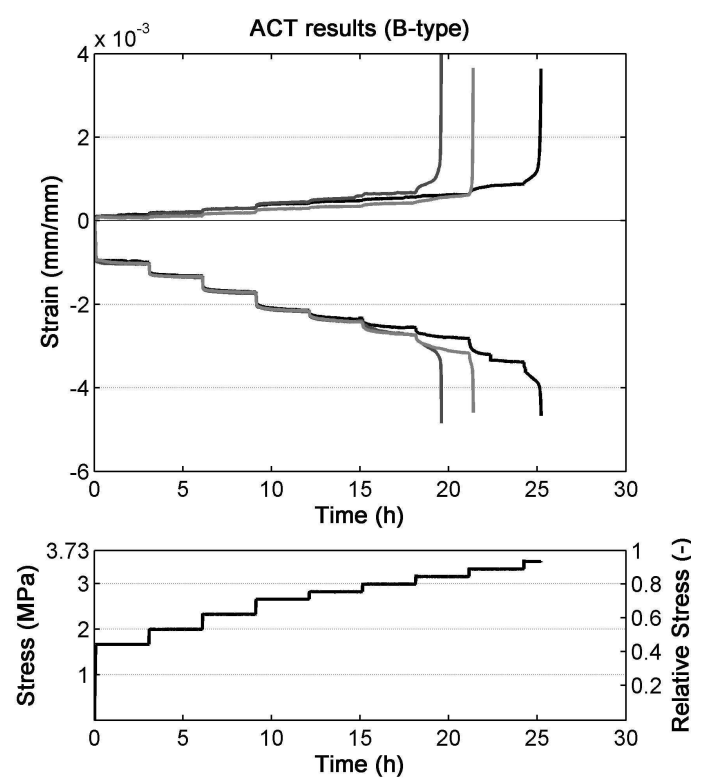

Fig. 6 Resulting time-dependent deformation behavior during $\mathrm{ACT}$. Results from 3 tests on B-type specimens and indication of stress path


Fig. 7 Resulting time-dependent deformation behavior during CACT. Results from 3 tests on A-type specimens and indication of stress path

Regarding all short-term creep tests, it has to be kept in mind that the average compressive strength, obtained from the compressive tests, is fixed as the $100 \%$ load level, but the scatter on the strength of the specimens complicates the execution of the creep tests and the analysis of the test results.

In Fig. 6 and 7, strain-time evolutions are indicated for ACT on three B-type specimens and CACT on three A-type specimens. Axial strains are presented negative, lateral strains positive. The stress path followed during 


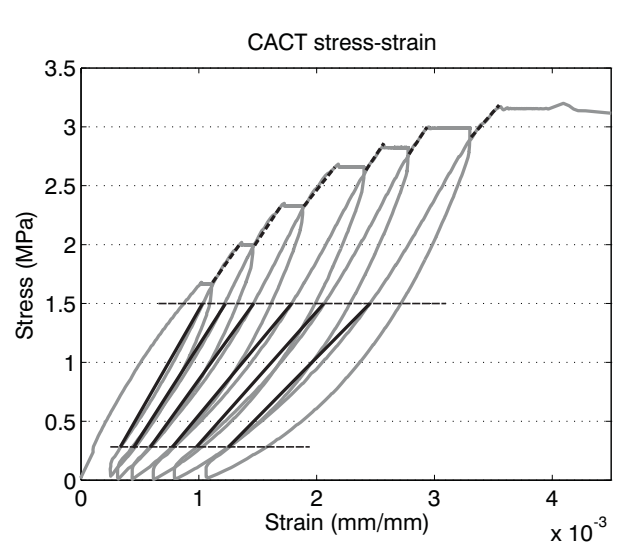

Fig. 8 Typical stress-strain graph from a cyclic accelerated creep test

the tests is indicated in the lower graphs, with an absolute (in $\mathrm{MPa}$ ) and a relative (the absolute value divided by $f_{c}$ ) scale on the $\mathrm{Y}$-axis. All steps of the creep curves show a primary creep phase with a decreasing strain rate and a secondary phase with a quasi constant rate. Some of the last steps also show a tertiary phase, with increasing strain rate, if the specimen did not fail during stress increase. These creep phases are discussed more detailed in Section 4.3.

The cyclic accelerated creep tests exhibit a similar time-dependent deformation behavior as observed during the accelerated creep tests (see Fig. 7). However, during the unloading phase, a part of the total strains is regained, while a second, increasing part of the deformation is not recovered upon unloading of the specimen. The former strain presents the elastic, immediate deformations, while the second part includes the timedependent creep strains (which could be partly regained if the unloading phase is maintained for a longer period). The results of the CACT give an indication of the evolution of the elastic modulus due to creep damage. A typical stress-strain graph from a CACT is indicated in Fig. 8. This graph illustrates that indeed the elastic modulus, which is the slope of the graph upon reloading decreases for the successive loading phases, indicating that damage has been introduced in the specimen. But when the upper parts of the slopes are considered (dotted lines between the previous maximum load and the maximum load of the present step), not much difference is found between the elastic moduli of the successive steps. The first observation is important when modeling cyclic loading, the second when modeling monotonic and sustained stresses.

The results of the accelerated creep tests with an additional cyclic loading are similar to the results from the ACT. Slightly larger strains were recorded upon failure due to the fatigue effect of the cyclic loading. Regarding the influence of the cyclic loading on the time to fail-

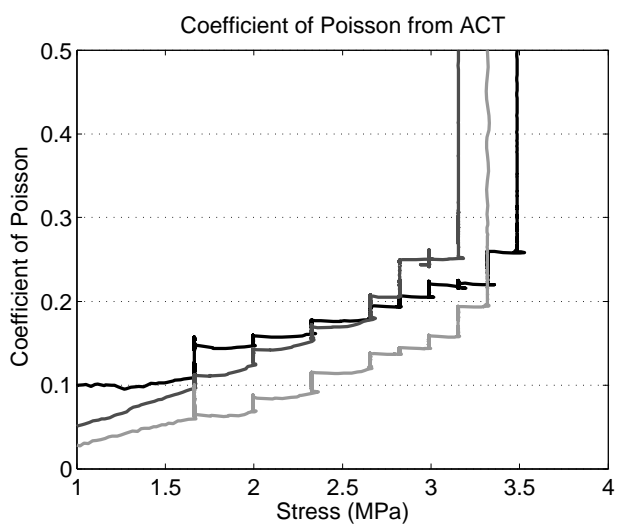

Fig. 9 Evolution of coefficient of Poisson during ACT on three B-type specimens

ure, no evidently shorter failure times or lower stress levels were recorded during the $\mathrm{ACT}+\mathrm{C}$ (see Table 3 ). For the fully carbonated, B-type masonry, higher load levels were reached during this test compared to the results of the ACT and CACT. For the A-type masonry, significant lower load levels were reached for the first two specimens, but a rather high level was reached for the third specimen.

Fig. 9 indicates the evolution of the Poisson coefficient in function of the stress level during three accelerated creep tests. The Poisson coefficient is calculated as the ratio between lateral and vertical strains and does not remain constant. The graph only starts at $1 \mathrm{MPa}$, as largely scattered values are found below this stress level, as the initial values, measured by the horizontal LVDT's, are very low and highly fluctuating. Generally, the Poisson coefficient starts around 0.05 and increases during the test up to 0.25 in the previous to last loading step. Finally, values up to 0.5 are reached when the specimen fails. This dilatation effect is generally observed during uniaxial compressive tests on masonry and is even more pronounced for uniaxial creep tests. From Fig. 9, it can be observed that the coefficient of Poisson increases most during the creep intervals, at constant stress, and the largest increase is observed in the previous to last constant stress interval.

\subsection{Analysis of creep curves}

To analyze the time-dependent strains in detail, typical stress-strain and strain-time graphs are drawn for the results of one accelerated (ACT) and one cyclic accelerated creep test (CACT) respectively. The strain-time evolution is presented on a 3 -hour scale for the subsequent steps separately, in order to analyze the evolution of the strain rates, see Fig. 10 and 11. 


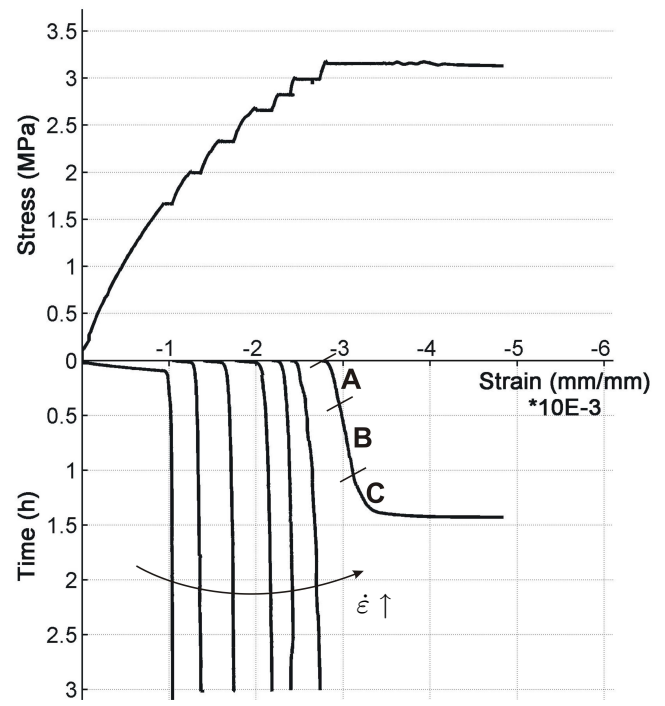

Fig. 10 Stress-strain and strain-time evolution during subsequent steps of $\mathrm{ACT}$ on B-type specimen, with indication of primary (A), secondary (B) and tertiary (C) phase

Each step shows two phases of a typical creep curve: a primary phase with decreasing strain rate just after the stress increase (A), and a secondary phase with constant strain rate (B). The last phase of the creep curve, the tertiary creep phase with increasing strain rate $(\mathrm{C})$, can only be observed during the last step of the test if the specimen did not fail during the stress increase. All three phases are indicated in the last step of the results of specimen B8 (Fig. 10). These phases are the basis of the structural model, presented in Section 5.1.

The creep damage is modelled with a parameter, called the viscous damage parameter, $D^{V}$. From the strain-time evolutions, it can be observed that the strain rates increase during subsequent steps of the creep test. This indicates that the strain rate depends on the stress level during the secondary phase of the creep curve. Therefore, the damage parameter will increase in function of the stress level. Secondly, the transition from secondary into tertiary creep phase can only be described if the damage accumulation is time-dependent and therefore, a rate-dependent damage formulation will be used. This results in a dual definition for the viscous damage, $D^{V}$.

\section{Viscoelastic modeling}

In this section, a short description is given of the viscoelastic model, used to simulate the creep tests and to model time-dependent deformation behavior in general. Given that a rather extensive test program has been set

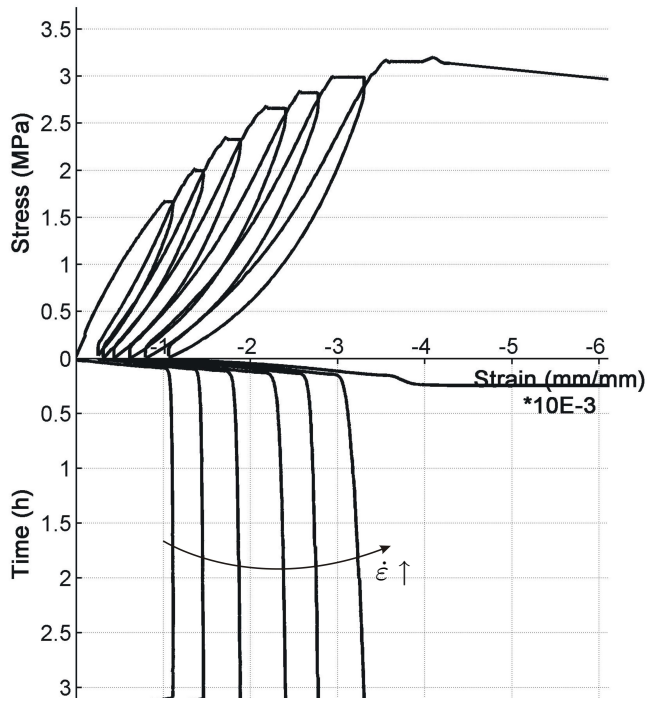

Fig. 11 Stress-strain and strain-time evolution during subsequent steps of CACT on B-type specimen

up to describe the model parameters, the scatter on the parameter values can be included in the analysis.

\subsection{Rheological model}

As an initial approach, a one-dimensional viscoelastic model is used to describe masonry's time-dependent behavior under uniaxial loading conditions. This type of basic rheological models has been used extensively in literature to explain and describe creep in rock [16] and time-dependent deformations in brittle materials such as concrete and masonry $[5,9,10,17]$. A phenomenological approach is often followed, as a complete understanding of the microstructural processes, which cause or influence creep deformations, is not at hand [4].

The experimental results indicated that masonry under high persistent loading follows a deformation pattern which can be described by the typical three-phase creep curve. It exhibits a primary creep phase during which the strain rate decreases in time, a secondary phase or steady-state creep, with a constant strain rate and a tertiary phase with an increasing strain rate, which leads to a sudden failure of the specimen. The primary creep phase can be modeled using a Kelvin component. This component is placed in series with a Maxwell spring-dashpot configuration, forming a rheological model which is able to simulate the elastic deformations and first two stages of the creep curve, see Fig. 12. To incorporate failure during the last stage of the three-phase creep process, Papa \& Taliercio proposed to incorporate damage variables in order to de- 


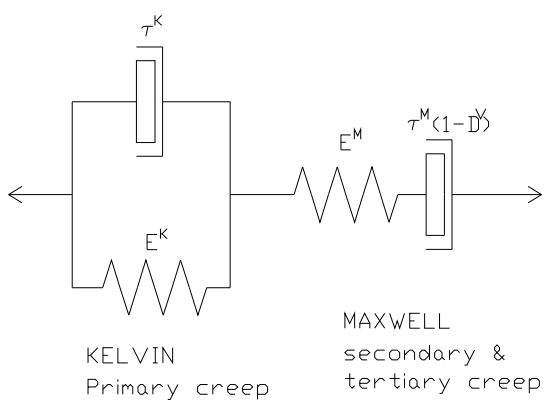

Fig. 12 Rheological creep model

scribe the decrease of the elastic and viscous material properties [10]. This approach will be followed here by introducing a viscous damage parameter, $D^{V}$, which describes the damage accumulation as a function of stress level and time (see Section 5.2).

The analysis will focuss on the capability of the model to simulate the masonry's time-dependent behavior, without making adjustments to parameter values, which were objectively calculated from the experimental results. The scatter on the most important parameters will be included in the analysis, as the obtained result will be much more valuable if one is aware of its sensitivity on the scatter of the parameter values.

The basis differential equations, describing the rheological model, are:

Kelvin component:

$\sigma=E^{K} \varepsilon^{K}+\eta^{K} \dot{\varepsilon}^{K}$

Maxwell component:

$\dot{\varepsilon}^{M}=\frac{\dot{\sigma}}{E^{M}}+\frac{\sigma}{\eta^{M}}$

With $\eta=\tau E$ the viscosity. Elimination of $\varepsilon^{K}$ and $\varepsilon^{M}$ would result in a second order differential equation $[18,19]$. If it is assumed that a constant stress is applied at $t=0$ and all model variables remain constant in time, the differential equations can be integrated in a closed-form 1-dimensional constitutive formulation [10]:

$$
\begin{aligned}
\varepsilon(\sigma, t) & =\frac{\sigma}{E^{M}}+\frac{1}{E^{K}}\left(1-\exp \left(\frac{-t}{\tau^{K}}\right)\right) \sigma \\
& +\frac{t}{E^{M} \tau^{M}\left(1-D^{V}\right)} \sigma
\end{aligned}
$$

Where $E^{M / K}$ is the Maxwell $(M)$ or Kelvin $(K)$ elastic modulus and $\tau^{M / K}$ the Maxwell $(M)$ or Kelvin
$(K)$ time constant. The Maxwell relaxation time $\tau^{M}$ is replaced by a non-constant relaxation function $\tau^{M}(1-$ $D^{V}$ ), which introduces a rate- and stress dependency of the Maxwell component (see Section 5.2). If the stress or model variables do not remain constant during the considered time interval, the integration of the differential equation poses a more complex problem. To solve this issue, an incremental equation is integrated in closed form by assuming the model variables to remain constant within a small time increment. If a time increment $\Delta t_{i}=t_{i}-t_{i-1}$ is considered, the differential equations can be integrated in closed form using a backward Euler scheme and the total strain increment can finally be written as follows [10]:

$\Delta \varepsilon_{i}=\frac{\Delta \sigma_{i}}{E_{i}}+\Delta \varepsilon_{i}^{i n}$

A small strain increment $\Delta \varepsilon_{i}$ is a combination of an elastic strain increase $\frac{\Delta \sigma_{i}}{E_{i}}$ due to the stress increase in the considered time interval and an inelastic strain or creep increment $\Delta \varepsilon_{i}^{i n}$ due to the stress level at the beginning of the time interval. This implies that the time increment has to be taken as small as possible, as the internal state variables are considered to be constant during the time interval. Smaller time steps, on the other hand, will increase the calculation time. Therefore, the length of the time interval is taken as a compromise between accuracy and calculation time. The incremental model is implemented in Matlab (The MathWorks, version 2008a).

\subsection{Damage evolution}

A continuum damage approach is followed by combining the viscoelastic model with a damage parameter, $D^{V}$, which evolves from 0 (no damage) to 1 (total material failure) throughout the lifetime of the masonry [20]. A dual formulation is used for the description of the damage evolution. As experimental research has indicated that the strain rate depends on the stress level and damage accumulation can also trigger failure during constant stresses, the evolution of $D^{V}$ will be a function of stress and time. To describe the evolution of the strain rate during the secondary creep phase, $D^{V}$ was found to evolve linearly in function of the stress level $[9]$ :

$D^{V}=A \sigma^{*}+B$

with $\sigma^{*}$ being the dimensionless stress ratio, acquired by dividing the absolute stress by the average compressive strength, $f_{c}$, of the considered mortar type. 
Secondly, a damage rate formulation is adopted to describe the evolution of damage in function of time. This enables the simulation of damage increase when the stress level remains constant $[21,20]$ :

$\dot{D}=c s^{n}$

With $s$ being the effective stress, calculated according to:

$s=\frac{\sigma^{*}}{(1-D)}$

By using this damage rate formulation for the evolution of the viscous damage, $D^{V}$, the damage increment in $\Delta t_{i}$ can be implemented according to:

$$
\frac{\Delta D_{i}^{V}}{\Delta t_{i}}=c\left(\frac{\sigma^{*}}{1-D_{i-1}^{V}}\right)^{n}
$$

This simple formulation has the advantage that only two parameters, $c$ and $n$ have to be determined. Damage evolution is described using a power law equation. Alternatively, others have used an exponential equation for damage development under constant stress, see for example Anzani [17] and Bodner \& Chan [22].

\subsection{Parameter study}

From the experimental results described in Section 4, a set of parameter values was obtained to model the longterm deformation behavior of the uncarbonated (Atype) and carbonated (B-type) masonry. An overview of the values obtained and their standard deviation is given in Table 4. All values were calculated from the stress-strain and strain-time evolutions, monitored during the experiments with the LVDT's. The calculation of the parameters, describing the damage accumulation, is discussed in Section 5.3.2.

\subsubsection{Elastic moduli}

As mentioned in Section 4.3, not much difference is found between the elastic moduli of the successive steps of a cyclic accelerated creep test when the upper parts of the slopes of the stress-strain curves are considered. Therefore, no damage parameter will be used to describe the possible decrease of the elastic stiffness of the Maxwell component.
Table 4 Overview of the experimentally obtained parameter values: average (standard deviation)

\begin{tabular}{llll}
\hline \multicolumn{2}{l}{ model parameter } & A-type & B-type \\
\hline$f_{c}(\mathrm{MPa})$ & & $2.54(0.24)$ & $3.73(0.10)$ \\
$\nu(-)$ & & $0.15(0.05)$ & $0.2(0.05)$ \\
$\tau^{K}(\mathrm{~s})$ & & $15446(7185)$ & $34491(24170)$ \\
$E^{K}(\mathrm{MPa})$ & & $1500(300)$ & $2500(500)$ \\
$\tau^{M}(\mathrm{~s})$ & $T_{m_{-} a}$ & $1578(265)$ & $1491(117)$ \\
& $T_{m \_b}$ & $487560(184176)$ & $474270(101848)$ \\
$E^{M}(\mathrm{MPa})$ & & $1211(144)$ & $1868(224)$ \\
$D^{V}(-)$ & $A$ & $1.82(0.19)$ & $1.90(0.16)$ \\
& $B$ & $-0.83(0.14)$ & $-0.86(0.12)$ \\
& $c$ & $7.8 \mathrm{e}-11\left(0.5^{*} \mathrm{c}\right)$ & $7.8 \mathrm{e}-11\left(0.5^{*} \mathrm{c}\right)$ \\
& $n$ & $7\left(0.15^{*} \mathrm{n}\right)$ & $7\left(0.15^{*} \mathrm{n}\right)$ \\
\hline
\end{tabular}

\subsubsection{Damage parameter}

The calculation of the parameters $A$ and $B$ to describe the evolution of the viscous damage, $D^{V}$, in function of the stress level, according to Eq. (5), is discussed in this section. The Maxwell relaxation time, $\tau^{M}$, depends on the strain increment during the secondary creep phase, $\Delta \varepsilon_{\text {sec }}$, and the stress level, $\sigma$, according to the equation of the Maxwell dashpot:

$$
\Delta \varepsilon_{\mathrm{sec}}(\sigma, t)=\frac{\Delta t}{E^{M} \tau^{M}\left(1-D^{V}\right)} \sigma
$$

For each loading step of the short-term creep tests, $\tau^{M}\left(1-D^{V}\right)$, is calculated according to Eq. (9) between $1 / 3$ and $2.5 / 3$ of the duration of the secondary creep phase (see boundaries indicated in Fig. 13). Initially, these calculated values remain constant or increase slightly. After a few load steps, a maximum value is found for $\tau^{M}$, which is set as initial value. The decrease of the relaxation time within the next load step is then calculated as an increase of $D^{V}$. A graph presenting all points calculated according to this procedure is indicated in Fig. 14, together with the regression line which presents the linear relation between $D^{V}$ and the relative stress ratio, $\sigma^{*}$. The grey lines indicate the $95 \%$ confidence interval for the estimated curve and the dotted lines present the $95 \%$ prediction interval for new observations of $D^{V}$ at a given stress level.

Regarding the presented set of parameter values, Table 4, all standard deviations were experimentally obtained, except for $c$ and $n$. The calculation of these two parameters requires a large set of experimental results, which exhibit a long tertiary creep phase at different stress levels. This, of course, is very difficult to obtain. Therefore, the value of these parameters is based on the limited amount of experimental data available from accelerated creep tests and their scatter is taken as a 


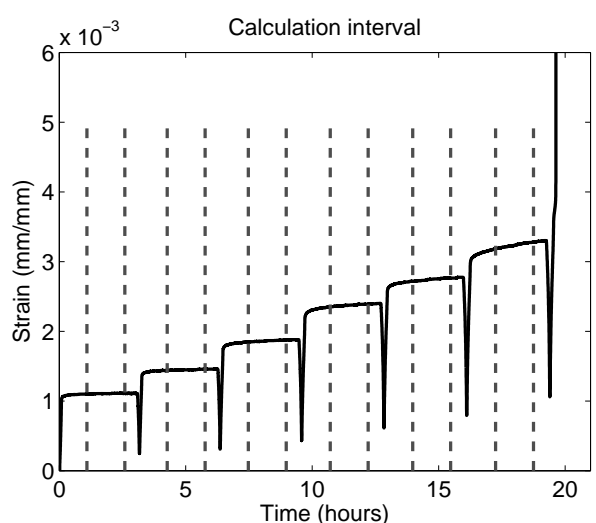

Fig. 13 Interval in which the strain increment is considered to calculate the evolution of $\tau^{M}$ (The interval for each load step is indicated by two dotted vertical lines)

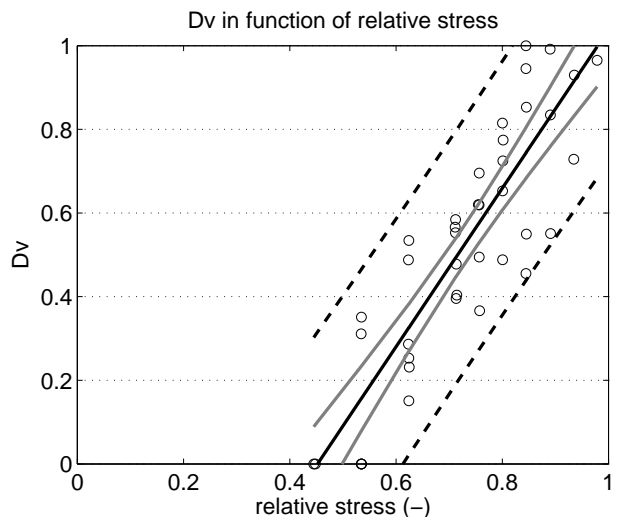

Fig. 14 Experimental results and regression line indicating the relation between $D^{V}$ and the relative stress level for B-type masonry

percentage of their average value, according to practical experience. The future availability of the results of ongoing long-term creep tests and additional accelerated creep tests, where the focus is on obtaining a tertiary creep phase, will enhance the estimated values and provide a better knowledge of their scatter. The values for $c$ and $n$ are taken equal for both A- and B-type mortars, as the stress level in Eq. (6) is the dimensionless stress, $\sigma^{*}$.

\subsubsection{Relaxation time}

The Maxwell time constant $\tau^{M}$ is described in function of time with two parameters $T_{m_{-} a}$ and $T_{m_{-} b}$, according to Eq. (10) [9]. The time constant increases less than linear with time, to describe the apparent increase in viscosity of the material. The minimum value, $T_{m_{-} b}$ is obtained from the accelerated creep tests. The maximum time constant, $\tau_{\max }^{M}$ is set equal to $5 \mathrm{e} 9 \mathrm{~s}$, which is approximately 150 years.
$\tau_{i}^{M}=T_{m_{-} a} \cdot t_{i}^{0.7}+T_{m_{-} b}$

It is important to remark that the execution of creep tests is rather difficult and laborious due to the size of the specimens, the duration of the tests, and the scatter on the material behavior. Therefore, obtaining a large, objective set of parameters is not readily done. Past research has greatly improved the effectiveness of the types of tests performed and the objectivity of the parameters estimated [23].

\section{Comparison of experimental and theoretical results}

In order to quantitatively evaluate the rheological model, simulations made with the model are compared with the experimental results from the short-term creep tests. To extend the time frame, the model is also used for the simulation of long-term creep tests, which had a duration of more than a year. In all model simulations, the parameter values, which were calculated from the shortterm creep tests, as indicated in Table 4, are used.

\subsection{Short-term simulations}

The experimental strain-time evolution of three B-type masonry specimens during an accelerated creep test is indicated in Fig. 15, together with the model simulation. Good correspondence is obtained between experimental and theoretical results. The failure time and axial strains are predicted well, the transversal strains are slightly overestimated at low stress values and underestimated at the end of the test as a constant coefficient of Poisson was used for the simulations. The dotted lines in Fig. 15 indicate simulations made with the 0.05 and 0.95 quantile values of variables $f_{c}$ and $E^{M}$ to validate their influence on the result. Their value affects the strain and in smaller degree the time to failure.

In Fig. 16, the experimental results of ACT on three A-type specimens are plotted together with the model simulation. The dotted lines indicate simulations made with the the 0.05 and 0.95 quantile values of variable $A$. This variable, describing the evolution of the viscous damage, $D^{V}$, in function of the stress level, has a larger influence on the failure time prediction. Although the experimental results are overestimated by the model in Fig. 16, their failure times are all within the upper and lower bounds of the simulation, given by the quantile values of the variable $A$. 


\subsection{Long-term simulations}

To evaluate whether the rheological model and the calculated parameter values can be used within larger time frames, the behavior during a series of long-term creep tests is predicted. These experimental results, presented in Fig. 17 and 18 are obtained from three long-term creep tests on A-type and B-type masonry. The tests are performed according to the same loading path followed during the short-term ACT's, the difference being that the stress level is kept constant during a time interval of 2 months instead of 3 hours. While the shortterm creep tests had a duration of 20-40 hours, these tests have a duration of approximately 1.5 years.

In both figures, the influence of variables $f_{c}$ and $E^{M}$ on the failure time prediction is indicated through an upper and lower bound simulation, made with their 0.05 and 0.95 quantile values. The experimental results of the B-type specimens are predicted well by the simulation, see Fig. 17. Though it has to be remarked that the elastic modulus is slightly underestimated and that the use of a constant coefficient of Poisson results in a poor prediction of the lateral strains. The scatter on the experimental results is also larger, compared with the short-term creep tests, but these fluctuations can be captured by the model through the upper and lower bound simulations. During the second load step, the experimental results show a strain rate which is larger than expected. This is a consequence of a malfunctioning climatisation system, which caused fluctuations in the relative humidity. As indicated in Section 3.2, this is not taken into account in the presented analysis.

The experimental results of the A-type specimens are preliminary results, as the tests are still ongoing Fig. 18. However, the deformations are very well simulated by the model and according to the simulation, the tests should be concluded within a few months. It is however doubtful whether the predicted strength levels for A-type masonry will be obtained at the end of the test, as the progressing carbonation process will simultaneously increase the long-term strength.

The results also indicate that a rather limited difference in load ( $5 \%$ of the strength value) distinguishes between failure or stability within the 2 month time interval. This indicates that decisions concerning longterm stability of masonry have to be taken very carefully and scatter on parameter values has to be taken into account.

\section{Remarks and conclusions}

To describe the time-dependent behavior of masonry constructed with lime mortar, a research program has

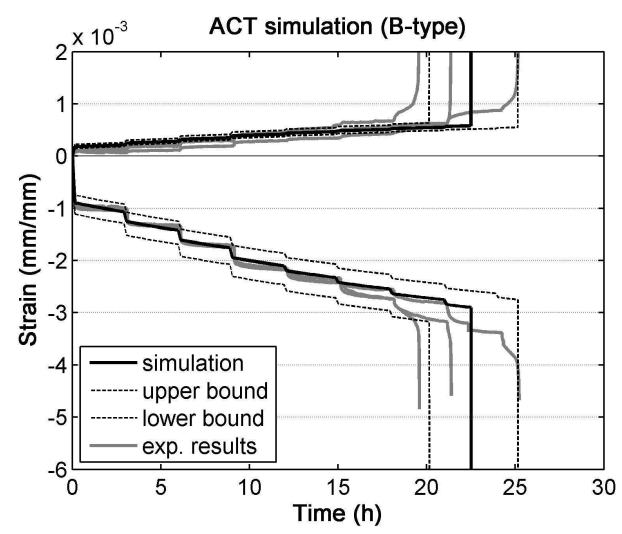

Fig. 15 Experimental results and simulation of short-term creep tests (ACT) on B-type masonry. Dotted lines indicate the upper and lower bounds of the scatter on model parameters $f_{c}$ and $E^{M}$

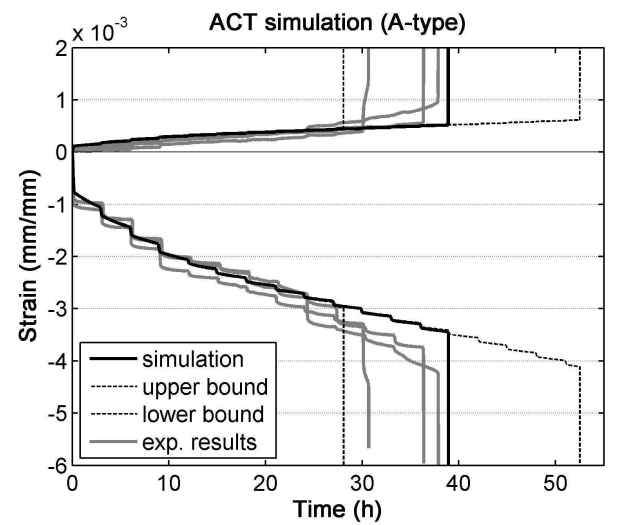

Fig. 16 Experimental results and simulation of short-term creep tests (ACT) on A-type masonry. Dotted lines indicate the upper and lower bounds of the scatter on model parameter $A$

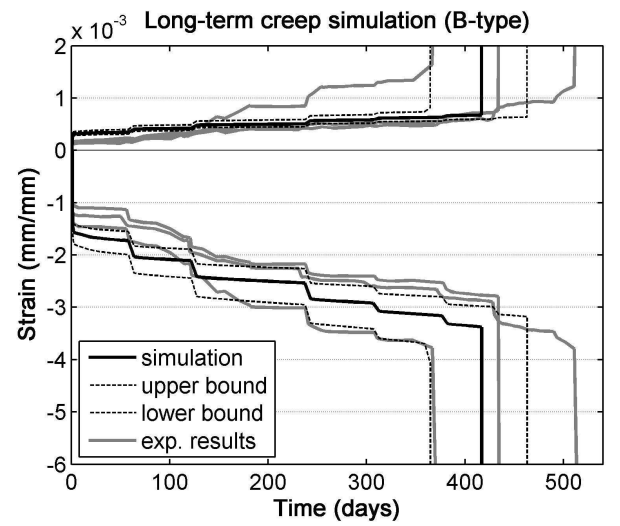

Fig. 17 Experimental results and simulation of long-term creep tests (ACT) on B-type masonry. Dotted lines indicate the upper and lower bounds of the scatter on model parameters $f_{c}$ and $E^{M}$ 


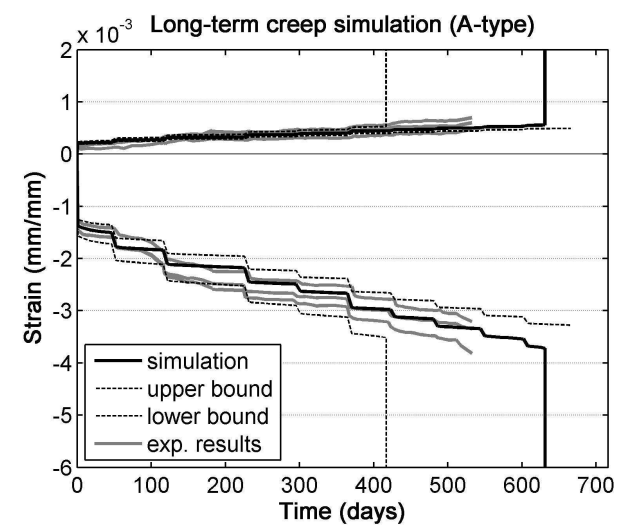

Fig. 18 Experimental results and simulation of ongoing longterm creep tests (ACT) on A-type masonry. Dotted lines indicate the upper and lower bounds of the scatter on model parameters $f_{c}$ and $E^{M}$

been set up involving compressive tests and a range of short-term creep tests. Experimental results indicated, as expected, a dependency of the strain rate and the failure time on the stress level. The large set of experimental results enabled the determination of average parameter values to be used as input for a viscoelastic creep model. Based on the observations from the shortterm creep tests, a damage parameter was included in the model, describing the damage evolution as a function of the applied stress level and of the damage rate.

The advantage of the rheological model is its ability to present the observed phenomenon of instantaneous and time-dependent behavior in a straightforward manner. Model parameters have a physical meaning and can be derived from experimental tests. But a drawback is the large number of model parameters needed and the unawareness of the outcome on their scatter. Simulations have indicated that the viscoelastic model with damage is able to predict the experimental results rather well and shows good qualitative results in long-term simulations. Simulation of upper and lower boundaries of important parameters have also indicated that the scatter on the material parameters has a rather large influence on the final predictions.

Future research will focuss on the implementation of the presented model in a 3 dimensional environment, to enable inclusion in a finite element analysis. Hereby, the influence of multi-axial stress situations and the effect of dilatation should be investigated in a more detailed manner.

Finally, the results indicate that a rather limited difference in load has a large influence on the expected failure time. This indicates that assessing the long-term stability of masonry has to be done very carefully and that a past long life time is no guarantee for future safety.
Acknowledgements The authors express their thanks to the Flemish Fund for Scientific Research (FWO) for the doctoral grant, offered to Els Verstrynge. The authors highly appreciate the collaboration with the Politecnico di Milano and the University of Minho in this research area.

\section{References}

1. L. Binda. Learning from Failure - Long-term behaviour of heavy masonry structures, volume 23 of Advances in Architecture. WIT Press, Southampton, 2008.

2. A. Anzani, L. Binda, and G. M. Roberti. The effect of heavy persistent actions into the behaviour of ancient masonry. $M a$ terials and Structures, 33(228):251-261, 2000.

3. J. Pina-Henriques and P. B. Lourenco. Testing and modelling of masonry creep and damage in uniaxial compression. Structural Studies, Repairs and Maintenance of Heritage Architecture Viii, 16:151-160, 2003.

4. G. P. A. G. van Zijl. Computational modelling of masonry creep and shrinkage. Phd, 2000.

5. K. K. Choi, S. L. Lissel, and M. M. R. Taha. Rheological modelling of masonry creep. Canadian Journal of Civil Engineering, 34(11):1506-1517, 2007.

6. D. Ferretti and Z. P. Bazant. Stability of ancient masonry towers: Moisture diffusion, carbonation and size effect. Cement and Concrete Research, 36(7):1379-1388, 2006.

7. E. Verstrynge, S. Ignoul, L. Schueremans, D. Van Gemert, and M. Wevers. Application of the acoustic emission technique for assessment of damage-accumulation in masonry. International Journal for Restoration of Buildings and Monuments, 14(3):167-178, 2008.

8. A. Anzani, L. Binda, and G. M. Roberti. A numerical interpretation of long-term behaviour of masonry materials under persistent loads. Structural Studies of Historical Buildings IV - vol 1: Architectural Studies, Materials and Analysis, pages 179-186, 1995.

9. E. Verstrynge, S. Ignoul, L. Schueremans, and D. Van Gemert. Modelling of damage accumulation in masonry subjected to a long-term compressive load. In D. D'Ayala and E. Fodde, editors, 6th International Seminar on Structural Analysis of Historical Constructions, pages 525-532, Bath, 2008

10. E. Papa and A. Taliercio. A visco-damage model for brittle materials under monotonic and sustained stresses. International Journal for Numerical and Analytical Methods in Geomechanics, 29(3):287-310, 2005.

11. E. Garavaglia, A. Anzani, and L. Binda. Probabilistic model for the assessment of historic buildings under permanent loading. Journal of Materials in Civil Engineering, 18(6):858-867, 2006.

12. E. Verstrynge, L. Schueremans, and D. van Gemert. Service life prediction of masonry under high loading: modelling and probabilistic evaluation. In 10th International Conference on Structural Safety and Reliability, Osaka, 2009.

13. K. van Balen, B. van Bommel, R. van Hees, M. van Hunen, J. van Rhijn, and M. van Rooden. Kalkboek: Het gebruik van kalk als bindmiddel voor metsel- en voegmortels in verleden en heden (in Dutch). Rijksdienst voor Monumentenzorg, Zeist, 2003.

14. K. Van Balen and D. Van Gemert. Modeling lime mortar carbonation. Materials and Structures, 27(171):393-398, 1994.

15. J. P. Forth, J. J. Brooks, and S. H. Tapsir. The effect of unit water absorption on long-term movements of masonry. Cement and Concrete Composites, 22(4):273-280, 2000. 
16. G. N. Boukharov, M. W. Chanda, and N. G. Boukharov. The three processes of brittle crystalline rock creep. International Journal of Rock Mechanics and Mining Sciences and Geomechanics Abstracts, 32(4):325-335, 1995.

17. A. Anzani, L. Binda, and A. Taliercio. Application of a damage model to the study of the long term behaviour of ancient towers. In 1st Canadian Conference on Effective Design of Structures, Ontario, 2005.

18. D.R. Bland. The theory of linear viscoelasticity, volume 10 of Pure and applied mathematics. Pergamon Press, 1960.

19. Nicholas Tschoegl. The phenomenological theory of linear viscoelastic behavior. Springer-Verlag, Berlin, 1989.

20. D. Krajcinovic and J. Lemaitre. Continuum Damage Mechanics: Theory and Applications. Springer - Verlag, Berlin, 1987.

21. N. Challamel, C. Lanos, and C. Casandjian. Creep damage modelling for quasi-brittle materials. European Journal of Mechanics a-Solids, 24(4):593-613, 2005.

22. S. R. Bodner and K. S. Chan. Modeling of continuum damage for application in elastic-viscoplastic constitutive equations. Engineering Fracture Mechanics, 25(5-6):705-712, 1986.

23. L. Binda, L. Schueremans, E. Verstrynge, S. Ignoul, D. V. Oliveira, P. B. Lourenco, and C. Modena. Long term compressive testing of masonry - test procedure and practical experience. In D. D'Ayala and E. Fodde, editors, 6th International Seminar on Structural Analysis of Historical Constructions, pages 1345-1355, Bath, 2008. 